\title{
Efficacy and safety of etanercept in psoriasis and psoriatic arthritis in the PRESTA study: analysis in patients from Central and Eastern Europe
}

Nemanja Damjanov, Sarolta Karpati, Lajos Kemeny, Noemi Bakos, Branislav Bobic, Maria Majdan, Witold Tlustochowicz, Petr Vitek, Eva Dokoupilova, Emre Aldinc \& Annette Szumski

To cite this article: Nemanja Damjanov, Sarolta Karpati, Lajos Kemeny, Noemi Bakos, Branislav Bobic, Maria Majdan, Witold Tlustochowicz, Petr Vitek, Eva Dokoupilova, Emre Aldinc \& Annette Szumski (2018) Efficacy and safety of etanercept in psoriasis and psoriatic arthritis in the PRESTA study: analysis in patients from Central and Eastern Europe, Journal of Dermatological Treatment, 29:1, 8-12, DOI: $10.1080 / 09546634.2017 .1329509$

To link to this article: https://doi.org/10.1080/09546634.2017.1329509

Accepted author version posted online: 16

May 2017.

Published online: 16 Aug 2017.

Submit your article to this journal $\pi$

山 Article views: 216

Q View related articles ๘

View Crossmark data \lceil 


\title{
Efficacy and safety of etanercept in psoriasis and psoriatic arthritis in the PRESTA study: analysis in patients from Central and Eastern Europe
}

\author{
Nemanja Damjanov ${ }^{a}$, Sarolta Karpati ${ }^{b}$, Lajos Kemeny ${ }^{c}$, Noemi Bakos $^{d}$, Branislav Bobic ${ }^{e}$, Maria Majdan $^{f}$, \\ Witold Tlustochowicz ${ }^{\mathrm{g}}$, Petr Vitek ${ }^{\mathrm{h}}$, Eva Dokoupilovai, Emre Aldinc ${ }^{\mathrm{j}}$ and Annette Szumski ${ }^{\mathrm{k}}$
}

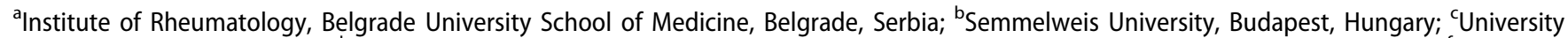
of Szeged, Szeged, Hungary; ${ }^{\mathrm{d}}$ Geza Jasz-Nagykun-Szolnok Hospital, Szolnok, Hungary; ${ }^{\mathrm{e}}$ Clinical Center Vojvodina, Novi Sad, Serbia; ${ }^{\mathrm{f}}$ Medical University of Lublin, Lublin, Poland; ${ }^{9}$ Klinika Chorob Wewnetrznych i Reumatologii, Centralny Szpital Kliniczny MON Wojskowy Instytut Medyczny, Warsaw, Poland; ${ }^{h}$ Centrum Rehabilitace, Padelky, Czech Republic; ${ }^{\mathrm{i}}$ Medical Plus, Uherske Hradiste, Czech Republic; ${ }^{\mathrm{j}} \mathrm{Global}$ Innovative Pharma, Pfizer, New York, NY, USA; kinVentiv Health, Princeton, NJ, USA

\begin{abstract}
Background: Data are limited on the effectiveness of anti-TNF and other biologics on psoriatric arthritis (PsA) in Central and Eastern Europe (CEE). The objective of this analysis was to evaluate the efficacy of etanercept (ETN) in PsA patients from CEE.

Methods: In PRESTA, patients were randomized to receive ETN $50 \mathrm{mg}$ BIW or $50 \mathrm{mg}$ QW for 12 weeks (double-blind phase) and ETN $50 \mathrm{mg} \mathrm{QW}$ for 12 additional weeks (open label). In this analysis, only patients from Czech Republic, Hungary, Poland and Serbia were included. The primary efficacy variable was the proportion of subjects achieving a physician global assessment (PGA) of psoriasis status: "clear" or "almost clear" at week 12.

Results: In the 307 patients, 54\% BIW/QW compared with 40\% (QW/QW) ( $p=.02)$, achieved "clear"/ "almost clear" for PGA of psoriasis at week 12 increasing, to $68 \%$ and $60 \%$, respectively $(p=.134)$ by week 24. Mean improvement from baseline in PASI were 59\% versus $49 \%(p=.005)$ at week 6 and $87 \%$ versus $81 \%(p<.05)$ at week 24 , for the BIW/QW and QW/QW groups, respectively. ETN was well tolerated in both groups over 24 weeks.

Conclusions: Both dose regimens of ETN provided significant improvements in efficacy in PsA treatment and were well tolerated.
\end{abstract}

\section{ARTICLE HISTORY}

Received 10 March 2017

Accepted 1 May 2017

\section{KEYWORDS}

Efficacy; etanercept; psoriatic arthritis; safety

\section{Introduction}

Psoriatic arthritis (PsA) is a chronic, progressive, inflammatory arthropathy affecting up to $40 \%$ of patients with skin or nail psoriasis (1). If not treated adequately, joint disease in PsA can lead to irreversible bone damage resulting in compromised physical function and a reduced quality of life.

The need to treat two diseases simultaneously can make the comanagement of PsA and psoriasis challenging. The presence of elevated tumor necrosis factor (TNF) levels in both psoriatic skin lesions and synovial fluid from joints affected by PsA has led to the use of anti-TNF biologics to treat both skin and joint manifestations (2-5). Although the effectiveness of anti-TNF agents and other biologics is well established through clinical trials in the USA and Western Europe, there are relatively few data related to other parts of the world, such as Central and Eastern Europe (CEE).

In the PRESTA (Psoriasis Randomized Etanercept Study in Subjects with Psoriatic Arthritis) study, two dose regimens of etanercept (ETN) were evaluated (ETN $50 \mathrm{mg}$ twice weekly [BIW] for 12 weeks followed by ETN $50 \mathrm{mg}$ once weekly [QW] or ETN $50 \mathrm{mg}$ QW for 24 weeks) (6). Both dose groups showed significant improvements in skin and joint symptoms and quality of life measures with no new safety signals. PRESTA was a multinational trial that included patients from countries in CEE. The objective of this subset analysis is to evaluate the efficacy of ETN therapy in patients from these countries compared with the overall study population.

\section{Methods}

\section{Study group}

The details of the PRESTA trial (Clinicaltrials.gov Identifier: NCT00245960) have been previously published (6). PRESTA was a randomized, 24-week, multicenter study enrolling adult ( $\geq 18$ years of age) patients diagnosed with active but stable plaque psoriasis involving at least $10 \%$ of body surface area and a physician's global assessment (PGA) of psoriasis of moderate-tosevere at baseline. In addition, all patients had active PsA defined as $\geq 2$ swollen joints, $\geq 2$ tender joints, joint pain for $\geq 3$ months and a negative serum rheumatoid factor within 6 months prior to screening. Patients were randomized to receive ETN $50 \mathrm{mg}$ BIW or $50 \mathrm{mg} \mathrm{QW}$ for 12 weeks in a double-blind phase and openlabel ETN $50 \mathrm{mg}$ QW for 12 additional weeks. For this post hoc analysis, only patients who participated in PRESTA from four CEE countries (Czech Republic, Hungary, Poland and Serbia) were included. 


\section{Efficacy and safety assessments}

The primary efficacy variable was the proportion of subjects who achieved a PGA of "clear" or "almost clear" at week 12. This assessment was reported on a scale ranging from 0 to 5 , with 0 indicating no psoriasis (clear skin), 1 being almost clear and 5 indicating severe disease.

Secondary endpoints reported in this subset analysis included the PGA status at week 24; mean percentage improvements from baseline in PGA; psoriasis area and severity index (PASI); PGA for arthritis, painful and swollen joints; enthesitis and dactylitis at weeks 12 and 24; proportion of patients who achieved PASI 50/ 75/90 response; American College of Rheumatology (ACR) 20/50/ 70 response and Psoriatic Arthritis Response Criteria (PsARC) response at weeks 12 and 24, as well as the change in C-reactive protein (CRP) levels. Safety assessments included physical examinations, laboratory analyses and reporting of adverse events (AEs) that was collected by telephone up to two weeks after the study.

\section{Statistical analysis}

Detailed information on the statistical analyses in the PRESTA study has been described previously (7). Efficacy and safety analyses were conducted on the modified intention to treat (mITT) population, which included all randomized subjects receiving $\geq 1$ dose of test drug and who had at least one postbaseline efficacy evaluation. Endpoint measurements that were based on the proportions of subjects were compared using the Mantel-Haenszel $\chi^{2}$ test. Analysis of covariance (ANCOVA) models using baseline value as covariant were used for continuous and ordinal endpoints. (ANOVA was used when the baseline value was not available.) Mean percent change was calculated from the change mean divided by baseline mean. Efficacy analyses used the last-observation-carried-forward approach for missing data imputation. Statistical testing was done at $\alpha=.05$ level, two-sided testing, without any adjustment for multiple comparisons unless otherwise specified.

\section{Results}

\section{Baseline demographics}

Of the 752 patients randomized to either the ETN $50 \mathrm{mg}$ BIW/QW or the ETN $50 \mathrm{mg}$ QW/QW arm in the PRESTA study, 307 patients from four CEE countries (Czech Republic, $n=51$; Hungary, $n=107$; Poland, $n=41$; Serbia, $n=108$ ) were included in this post hoc analysis. Baseline demographic and disease characteristics were balanced between the two treatment groups (Table 1).

\section{Efficacy assessments}

Skin

A significantly greater proportion of participants in the BIW/QW group (54\%) achieved a status of "clear" or "almost clear" for PGA of psoriasis at week 12 compared with those in the QW/QW group $(40 \%) \quad(p=.02)$ (Figure 1). By week 24, the proportions had increased to $68 \%$ versus $60 \%$, respectively $(p=.134)$. Mean percentage improvement from baseline in the PGA of psoriasis at week 12 was significantly greater in the BIW/QW group than in the QW/QW group ( $57 \%$ vs. $50 \%, p=.014)$. At week 24 , the mean percentage improvement from baseline in PGA of psoriasis was similar for both groups (64\% vs. $62 \%, p=.413$ ) (Table 2).

At week 6 , the mean improvement from baseline in PASI was significantly greater in the BIW/QW group than in the QW/QW
Table 1. Baseline demographics and disease characteristics.

\begin{tabular}{lcc}
\hline & ETN $50 \mathrm{mg}$ & ETN $50 \mathrm{mg}$ \\
Parameters & BIW/QW $(n=153)$ & QW/QW $(n=154)$ \\
\hline Age, years & $46.8(11.5)$ & $46.6(11.1)$ \\
Female gender, $n(\%)$ & $60(39.2)$ & $67(43.5)$ \\
BMI, kg/m ${ }^{2}$ & $27.6(4.7)$ & $28.1(5.6)$ \\
Duration of PsA, years & $7.0(6.8)$ & $7.0(6.4)$ \\
Duration of psoriasis, years & $19.7(11.8)$ & $18.7(12.6)$ \\
PGA of psoriasis & $3.6(0.7)$ & $3.7(0.6)$ \\
BSA affected by psoriasis, \% & $31.6(23.1)$ & $29.9(22.9)$ \\
PASI & $20.0(11.2)$ & $19.0(9.5)$ \\
Swollen joint count & $15.7(18.4)$ & $18.0(18.6)$ \\
Tender joint count & $23.3(21.1)$ & $24.5(20.3)$ \\
Previous topical steroids, $n(\%)$ & $97(63.4)$ & $81(52.6)$ \\
CRP, mg/L & $14.5(24.2)$ & $18.3(33.6)$ \\
\hline
\end{tabular}

All values shown are means (SD) unless otherwise stated. BIW: twice weekly; BSA: body surface area; CRP: C-reactive protein; ETN: etanercept; PASI: psoriasis area and severity index; PGA: physician global assessment; PsA: psoriatic arthritis; QW: once weekly.

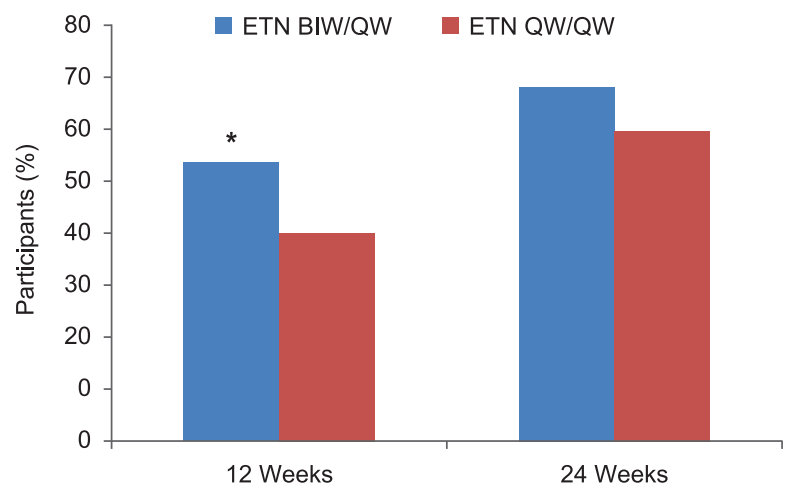

Figure 1. PGA psoriasis: participants achieving "clear" or "almost clear" responses at 12 weeks $\left({ }^{*} p=.02\right)$ and 24 weeks. LOCF data. BIW: twice weekly; ETN: etanercept; LOCF: last observation carried forward; PGA: physician's global assessment; QW: once weekly.

Table 2. Skin manifestations.

\begin{tabular}{lccr}
\hline & ETN $50 \mathrm{mg}$ & ETN $50 \mathrm{mg}$ & \\
Parameter & BIW/QW $(n=153)$ & QW/QW $(n=154)$ & $p$ value \\
\hline PGA psoriasis, Mean score $\%$ change from baseline) & & \\
Baseline & 3.63 & 3.69 & .364 \\
Week 12 & $1.57(56.7)$ & $1.85(49.9)$ & .014 \\
Week 24 & $1.30(64.2)$ & $1.43(61.5)$ & .413 \\
PASI, Mean score (\% change from baseline) & & \\
Baseline & 19.99 & 19.01 & .413 \\
Week 12 & $4.34(78.2)$ & $6.11(67.9)$ & $<.001$ \\
Week 24 & $2.85(85.7)$ & $3.74(80.3)$ & .036 \\
Patients achieving PASI response & & \\
PASI 50 & & $125 / 153(81.7)$ & .169 \\
Week 12 & $132 / 151(87.4)$ & $138 / 153(90.2)$ & .314 \\
Week 24 & $141 / 151(93.4)$ & & \\
PASI 75 & & $70 / 153(45.8)$ & $<.001$ \\
Week 12 & $98 / 151(64.9)$ & $110 / 153(71.9)$ & .068 \\
Week 24 & $122 / 151(80.8)$ & & \\
PASI 90 & & $31 / 153(20.3)$ & .022 \\
Week 12 & $48 / 151(31.8)$ & $67 / 153(43.8)$ & .006 \\
Week 24 & $90 / 151(59.6)$ & & \\
\hline
\end{tabular}

LOCF data. BIW: twice weekly; ETN: etanercept; PASI: psoriasis area and severity index; PGA: physician global assessment; QW: once weekly.

group ( $59 \%$ vs. $49 \%, p=.005)$; this difference between the two groups was maintained throughout the study up to week $24(87 \%$ vs. $81 \%, p<.05$ ) (Figure 2). At weeks 12 and 24, significantly greater proportions of participants in the ETN $50 \mathrm{mg}$ BIW/QW group than in the ETN $50 \mathrm{mg}$ QW/QW group achieved at least 90\% improvement in PASI; the BIW/QW regimen was also significantly more effective in helping patients attain a $75 \%$ 


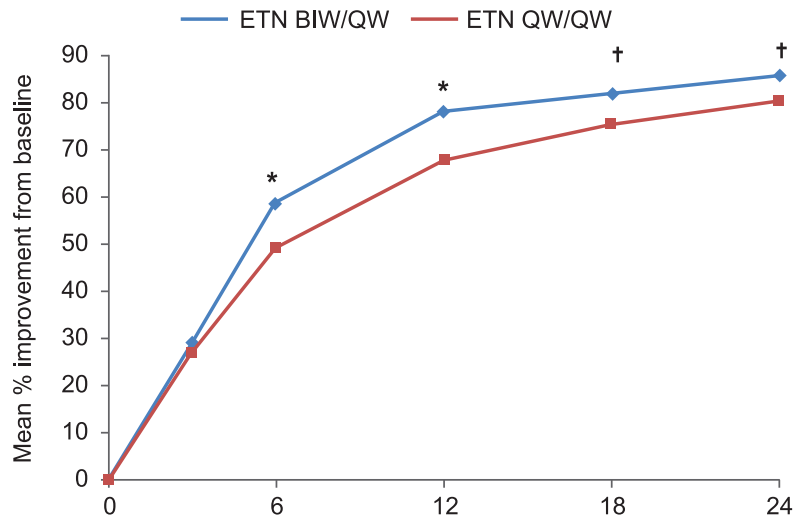

Figure 2. PASI: mean percentage improvement from baseline. LOCF data $*_{p}<.01 ;+p<.05$. BIW: twice weekly; ETN: etanercept; LOCF: last observation carried forward; PASI: psoriasis area and severity index; PGA: physician's global assessment; QW: once weekly.

improvement in PASI at week 12. There was no significant difference between the regimens in terms of PASI 50 response. The within-group changes from baseline in PGA of psoriasis and PASI were statistically significant at all study visits in both ETN groups $(p<.001$ for each).

\section{Joint and tendon rheumatic manifestations}

ACR 20 response at week 12 was significantly greater in the BIW/ QW group (71.7\%) than in the QW/QW group (59.9\%) $(p=.03)$, but similar between groups at week $24(77.6 \%$ vs. $75.7 \%)$ (Table 3). The proportions of participants who achieved ACR50 and ACR70 responses were similar in the two groups at weeks 12 and 24 (Table 3 ).

The proportion of participants who achieved PsARC was similar in the two groups at week 12 and remained stable at week 24 (Table 3). The mean percentage improvement from baseline in PGA of arthritis was similar in both groups at weeks 12 and 24 . There was no significant differences between the two ETN groups regarding the improvement from baseline in the swollen and painful joint counts, the percentage of subjects with enthesitis and the number of fingers/toes with dactylitis from the baseline and weeks 12 and 24 (Table 3). The within-group changes from baseline in PGA of arthritis and swollen and painful joint scores were statistically significant at weeks 12 and 24 in both ETN groups ( $p<.001$ for all).

CRP

Decreases from baseline in mean CRP levels were similar between the two treatment regimens and significant within each group. Concentrations decreased from 14.5 (SD 24.2) $\mathrm{mg} / \mathrm{L}$ at baseline to 5.0 (4.7) $\mathrm{mg} / \mathrm{L}$ by week 24 in the $50 \mathrm{mg} \mathrm{BIW/QW}$ group $(p<.001)$ and from $18.3(33.6) \mathrm{mg} / \mathrm{L}$ to $5.4(4.5) \mathrm{mg} / \mathrm{L}(p<.001)$ in the QW/ QW group.

\section{Safety assessments}

ETN was well tolerated in both treatment groups over 24 weeks. Lower $\mathrm{AE}$ rates were observed in both treatment groups compared to the overall PRESTA population; AEs were experienced in a higher proportion of patients in the BIW/QW group (36.6\%) than the QW/QW group $(24.7 \%)(p=.026)$; corresponding values in the total cohort were $56.2 \%$ in the BIW/QW group and $50.9 \%$ in the QW/QW group. The most commonly reported treatment-emergent adverse events $(\geq 5 \%$ in either treatment group) were upper respiratory tract infection, injection site reaction and pharyngitis; none of these was significantly different between treatment groups.
Table 3. Joint and tendon rheumatic manifestations.

\begin{tabular}{|c|c|c|c|}
\hline Parameter & $\begin{array}{c}\text { ETN } 50 \mathrm{mg} \\
\text { BIW/QW }(n=153)\end{array}$ & $\begin{array}{c}\text { ETN } 50 \mathrm{mg} \\
\text { QW/QW }(n=154)\end{array}$ & $p$ value \\
\hline \multicolumn{4}{|c|}{$\begin{array}{l}\text { Patients achieving ACR response, } n(\%) \\
\text { ACR } 20\end{array}$} \\
\hline Week 12 & $109 / 152(71.7)$ & $91 / 152(59.9)$ & .030 \\
\hline Week 24 & $118 / 152(77.6)$ & $115 / 152(75.7)$ & .685 \\
\hline \multicolumn{4}{|l|}{ ACR 50} \\
\hline Week 12 & 71/152 (46.7) & $56 / 152(36.8)$ & .082 \\
\hline Week 24 & $90 / 152(59.2)$ & $91 / 152(59.9)$ & .907 \\
\hline \multicolumn{4}{|l|}{ ACR 70} \\
\hline Week 12 & $33 / 152(21.7)$ & 29/152 (19.1) & .570 \\
\hline Week 24 & $60 / 152(39.5)$ & $58 / 152(38.2)$ & .814 \\
\hline \multicolumn{4}{|c|}{ Patients achieving PsARC, $n(\%)$} \\
\hline Week 12 & $126 / 153(82.4)$ & $117 / 154(76.0)$ & .170 \\
\hline Week 24 & $131 / 153(85.6)$ & $128 / 154(83.1)$ & .546 \\
\hline \multicolumn{4}{|c|}{ PGA arthritis, Mean score (\% change from baseline) } \\
\hline Baseline & 53.82 & 55.80 & .396 \\
\hline Week 12 & $19.55(63.6)$ & $21.65(61.2)$ & .489 \\
\hline Week 24 & $13.69(74.6)$ & $14.23(74.6)$ & .962 \\
\hline \multicolumn{4}{|c|}{ Painful joints, Mean score (\% change from baseline) } \\
\hline Baseline & 23.25 & 24.50 & .600 \\
\hline Week 12 & $9.63(58.8)$ & $11.50(53.3)$ & .350 \\
\hline Week 24 & $6.59(71.8)$ & $7.10(71.2)$ & .946 \\
\hline \multicolumn{4}{|c|}{ Swollen joints, Mean score (\% change from baseline) } \\
\hline Baseline & 15.69 & 18.01 & .275 \\
\hline Week 12 & $5.81(63.2)$ & $7.50(58.6)$ & .607 \\
\hline Week 24 & $3.98(74.8)$ & $3.82(78.9)$ & .412 \\
\hline \multicolumn{4}{|c|}{ Patients reporting enthesitis, $n(\%)$} \\
\hline Baseline & $74 / 153(48.4)$ & $69 / 154(44.8)$ & .532 \\
\hline Week 12 & $25 / 151(16.6)$ & $32 / 150(21.3)$ & .291 \\
\hline Week 24 & $16 / 146(11.0)$ & $15 / 148(10.1)$ & .818 \\
\hline \multicolumn{4}{|c|}{ Patients with dactylitis $>0$ (total number of fingers and toes) } \\
\hline & $N=61$ & $N=74$ & \\
\hline Baseline & $4.7(5.6)$ & $4.7(5.6)$ & - \\
\hline Week 12 & $1.8(4.2)$ & $2.1(4.8)$ & - \\
\hline Week 24 & $1.5(4.5)$ & $1.5(4.7)$ & - \\
\hline
\end{tabular}

LOCF data. ACR: American College of Rheumatology; BIW: twice weekly; ETN: etanercept; PGA: physician global assessment; PsARC: Psoriatic Arthritis Response Criteria; QW: once weekly.

A total of $13(8 \%)$ patients in the BIW/QW group and five (3\%) in the QW/QW group reported serious adverse events, including serious infections. Two (0.7\%) serious infections were reported, both (1.3\%) in the QW/QW group. One malignancy, a breast carcinoma in the BIW/QW group, was reported. No cases of tuberculosis, other opportunistic infections, or demyelinating disorders were reported and no participant died during the study.

\section{Discussion}

The effectiveness of ETN in the treatment of PsA, including the inhibition of radiographic disease progression, has been previously reported in a number of randomized clinical trials and observational studies. In this subset analysis of the PRESTA trial, we evaluated the efficacy and safety of two different ETN $(4,8,9)$ regimens in subjects from CEE with both moderate-to-severe psoriasis and active PsA. Overall, baseline demographics and disease characteristics were similar in the CEE population and the total PRESTA cohort, although the swollen and tender joint counts appeared to be higher in CEE subjects. While both ETN $50 \mathrm{mg}$ BIW/QW and $50 \mathrm{mg}$ QW/QW regimens significantly improved skin manifestations of psoriasis, the twice-weekly regimen had a significantly greater effect on the physician global assessment of psoriasis (at week 12) and PASI75 and PASI90 responses than the once-weekly treatment. Improvement from baseline in PASI was significantly greater in the BIW/QW group than in the QW/QW group after six weeks of treatment and this difference between regimens was maintained up to week 24. These findings are similar to those 
reported for the overall PRESTA study although a significant difference between the two regimens was observed up to week 12 in the total population.

Both ETN regimens achieved improvements from baseline in various joint components. However, apart from ACR 20 response at week 12, there were no significant differences between treatment groups in effects on joint manifestations: ACR50 and ACR70 responses were similar in the BIW/QW and QW/QW groups, as were swollen and painful joint scores and levels of enthesitis and dactylitis. Improvement observed in PsARC was also similar with both regimens.

These findings are similar to those of the overall PRESTA study. In 754 patients randomized at 98 sites worldwide, ETN $50 \mathrm{mg}$ administered twice weekly provided greater improvement in skin outcomes than once-weekly administration but similar effects on joint outcomes. Further analyses have shown that the beneficial effects of ETN on skin and joint manifestations have enhanced the quality of life of patients with PsA. Both ETN $50 \mathrm{mg}$ BIW/QW and $50 \mathrm{mg}$ QW/QW have been shown to provide sustained improvements in skin-related, patient-reported health outcomes within three weeks of commencing therapy (10). ETN treatment also resulted in reductions in the time taken off sick and job responsibility changes due to disease (11).

Overall, both ETN regimens were safe and well tolerated. Reported adverse event rates in patients from CEE were lower than those reported in the total PRESTA population (6). The explanation for this difference is not readily apparent. Unlike in the overall study, the proportion of patients experiencing adverse events was significantly higher in the BIW/QW group than the QW/QW group.

Evidence suggests that RA patients are generally in poorer health in CEE countries than in Western European countries, and one possible cause is the slower and more restricted utility of biological treatments. Data indicate that uptake of biologics for the treatment of RA is markedly lower in CEE countries $(1-5 \%$ of patients) than in Western Europe (11-12\%) (12), and it is reasonable to suppose that a similar if not greater disparity exists for the management of PsA. Concerns have also been raised about the substantial variability across CEE countries in access to biologic therapy for the treatment of inflammatory bowel disease (13). The limited use of biologics in CEE has been attributed not only to varying economic conditions across geographical locations but also to other determining factors, such as restrictive national clinical guidelines, administrative obstacles and availability of care (12).

Overall, there continues to be a shortage of data on the utility of TNF $\alpha$ inhibitors for the management of inflammatory rheumatic diseases in CEE populations. While some progress has been made in certain countries, the paucity of published data is still concerning. With the lack of clinical analyses and health economic evaluations the management of PsA remains a major issue (14). In view of the large gaps in basic information, there is an urgent need to perform more studies focusing specifically on CEE populations or post hoc analyses of larger multinational trials such as reported here.

In conclusion, the study in PSA patients from CEE demonstrated that both ETN dose regimens provided significant improvements in treatment efficacy without new safety signals. Clinical improvement in skin manifestations occurred earlier and was greater in those patients receiving ETN $50 \mathrm{mg}$ BIW/QW compared with patients receiving $50 \mathrm{mg}$ QW/QW. Both treatments were well tolerated. These data suggest that ETN is effective for the treatment of PSA in populations from regions where prior data are limited and will improve the quality of treatment of these patients. We hope that our findings help to address the dearth of information on the efficacy and safety of TNF $\alpha$ inhibitors in the management of PSA in CEE and ensure that treatment recommendations for the use of biologic drugs in PSA in CEE are allowed to be based on evidence-based decision making, rather than limited by financial constraints.

\section{Acknowledgements}

We wish to thank all patients who participated in the trial and investigators of the participating centers.

\section{Disclosure statement}

ND has received grant support from Pfizer, MSD, Abbvie, Roche; consultant fees from Pfizer, Abbvie, Roche; speaker fees from Pfizer, MSD, Abbvie, Roche, Gedeon Richter, Boehringer Ingelheim. SK has received institutional funding for research and/or honoria for consulting/and or conference support from Novartis, BristolMayer Squibb, Pfizer, Janssen. LK has received honoraria from Pfizer, Novartis, Abbvie, Janssen, Lilly, Galderma, Richter, Ewopharma Ltd. NB has no disclosures. BB has received research support from Pfizer, J\&J, Abbvie, Ablinx; speaker fees from Gedeon Richter, Boehringer Ingelheim. MM has received consultancy fees from Roche, MSD, Celgene, Pfizer; speaker fees from MSD, Roche, Medac, Pfizer, Abbvie, UCB, Berliner Chemie; investigator fees from Sanofi, BMS, UCB, HGS. WT has received honorarium from Pfizer and Biogen; congress participation sponsorship from Roche and Abbvie; speaker fees from Roche, Medac, Gedeon Richter.

ED has received investigator fees from Pfizer. PV has no disclosures. AS is an employee of inVentiv Health and was a paid contractor of Pfizer to provide statistical support for the development of this paper. EA is a full-time employee of Pfizer.

\section{Funding}

The PRESTA study was sponsored by Pfizer. Medical writing support was provided by John Bilbruck and Paul Oakley of Engage Scientific Solutions, and was funded by Pfizer.

\section{References}

1. Lee S, Mendelsohn A, Sarnes E. The burden of psoriatic arthritis: a literature review from a global health systems perspective. P T. 2010;35:680-9.

2. Kavanaugh A, Mclnnes I, Mease $P$, et al. Golimumab, a new human tumor necrosis factor alpha antibody, administered every four weeks as a subcutaneous injection in psoriatic arthritis: twenty-four-week efficacy and safety results of a randomized, placebo-controlled study. Arthritis Rheum. 2009;60:976-86.

3. Mease PJ, Gladman DD, Ritchlin CT, et al. Adalimumab for the treatment of patients with moderately to severely active psoriatic arthritis: results of a double-blind, randomized, placebo-controlled trial. Arthritis Rheum. 2005;52:3279-89.

4. Mease PJ, Kivitz AJ, Burch FX, et al. Etanercept treatment of psoriatic arthritis: safety, efficacy, and effect on disease progression. Arthritis Rheum. 2004;50:2264-72.

5. Antoni CE, Kavanaugh A, Kirkham B, et al. Sustained benefits of infliximab therapy for dermatologic and articular manifestations of psoriatic arthritis: results from the infliximab 
multinational psoriatic arthritis controlled trial (IMPACT). Arthritis Rheum. 2005;52:1227-36.

6. Sterry W, Ortonne JP, Kirkham B, et al. Comparison of two etanercept regimens for treatment of psoriasis and psoriatic arthritis: PRESTA randomised double blind multicentre trial. BMJ. 2010;340:c147.

7. Clegg DO, Reda DJ, Mejias E, et al. Comparison of sulfasalazine and placebo in the treatment of psoriatic arthritis. A Department of Veterans Affairs Cooperative Study. Arthritis Rheum. 1996;39:2013-20.

8. Mease PJ, Goffe BS, Metz J, et al. Etanercept in the treatment of psoriatic arthritis and psoriasis: a randomised trial. Lancet. 2000;356:385-90.

9. Mazzotta A, Esposito M, Schipani C, Chimenti S. Long-term experience with etanercept in psoriatic arthritis patients: a 3-year observational study. J Dermatolog Treat. 2009;20: 354-8.
10. Gniadecki R, Robertson D, Molta CT, et al. Self-reported health outcomes in patients with psoriasis and psoriatic arthritis randomized to two etanercept regimens. J Eur Acad Dermatol Venereol. 2012;26:1436-43.

11. Boggs RL, Kárpáti $\mathrm{S}$, Li W, et al. Employment is maintained and sick days decreased in psoriasis/psoriatic arthritis patients with etanercept treatment. BMC Dermatol. 2014;14:14.

12. Orlewska E, Ancuta I, Anic B, et al. Access to biologic treatment for rheumatoid arthritis in Central and Eastern European (CEE) countries. Med Sci Monit. 2011;17:SR1-13.

13. Rencz F, Péntek $M$, Bortlik $M$, et al. Biological therapy in inflammatory bowel diseases: access in Central and Eastern Europe. World J Gastroenterol. 2015;21:1728-37.

14. Péntek $M$, Poór $G$, Wiland $P$, et al. Biological therapy in inflammatory rheumatic diseases: issues in Central and Eastern European countries. Eur J Health Econ. 2014;15: S35-43. 